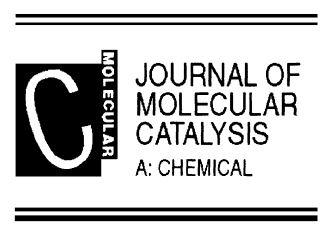

www.elsevier.com/locate/molcata

\title{
On the mechanism of carboxylic acid co-catalyst assisted metalloporphyrin oxidations
}

\author{
António M. d'A. Rocha Gonsalves*, Arménio C. Serra \\ Departamento de Química, Faculdade de Ciências e Tecnologia, Universidade de Coimbra, \\ Rua Larga, P-3000 Coimbra, Portugal
}

Received 4 August 2000; accepted 29 September 2000

\begin{abstract}
The role of the carboxylic acid as co-catalyst in metalloporphyrin catalytic hydrogen peroxide oxidations is discussed, taking into account its dependence on the ratio relatively to the catalyst. The catalytic efficiency and stability of the catalyst in the presence of an excess of carboxylic acid suggests that a metallo-acylperoxo complex can be the effective oxidation intermediate. (c) 2001 Elsevier Science B.V. All rights reserved.
\end{abstract}

Keywords: Metalloporphyrin; Catalysis; Hydrogen peroxide; Oxidation

\section{Introduction}

It has been generally accepted that the mechanism of catalytic oxidation by metalloporphyrins involves a metallo-oxo structure as the direct substrate oxidant. This basic structure may vary between the one having a pure oxo character such as in manganese metalloporphyrins [1-3] and that with a marked radical nature such as in iron-porphyrin complexes [4-7]. In similar oxygenation systems based on the manganese salen catalyst the role of a metallo-oxo complex as intermediate was also discussed [8-10].

However, the role of metallo-oxo species as the oxidative intermediate in catalytic metalloporphyrin oxidations has already been questioned and other intermediates have been suggested [11-14]. Our previous results on the study of hydrogen peroxide oxidations catalysed by metalloporphyrins in a two-phase system assisted by a carboxylic acid co-catalyst [15]

\footnotetext{
${ }^{*}$ Corresponding author. Fax: +351-239-826068.

E-mail address: arg@qui.uc.pt (A.M. d'A. Rocha Gonsalves).
}

suggest that the metallo-acylperoxo species involved is not a simple precursor of the metallo-oxo direct oxidative species (Scheme 1), as explained by the more generally accepted mechanism.

In this paper, we report further studies of hydrogen peroxide epoxidations in a two-phase system and manganese porphyrins ( $\mathbf{1}$ and $\mathbf{2}$ ) as catalysts (Scheme 2), which support the hypothesis of metallo-acylperoxo complex (I) being the direct oxidative species.

\section{Results and discussion}

As previously observed, oxidations by $5 \%$ hydrogen peroxide catalysed by manganese porphyrins are much faster if an excess of benzoic acid co-catalyst relatively to metalloporphyrin is used [15]. If we take the most commonly accepted mechanism for these catalysed oxidations, the large concentration of benzoic acid would increase the rate of the reaction because it benefits the formation of the metallo-oxo intermediate (II) $[16,17]$ (Scheme 3). 


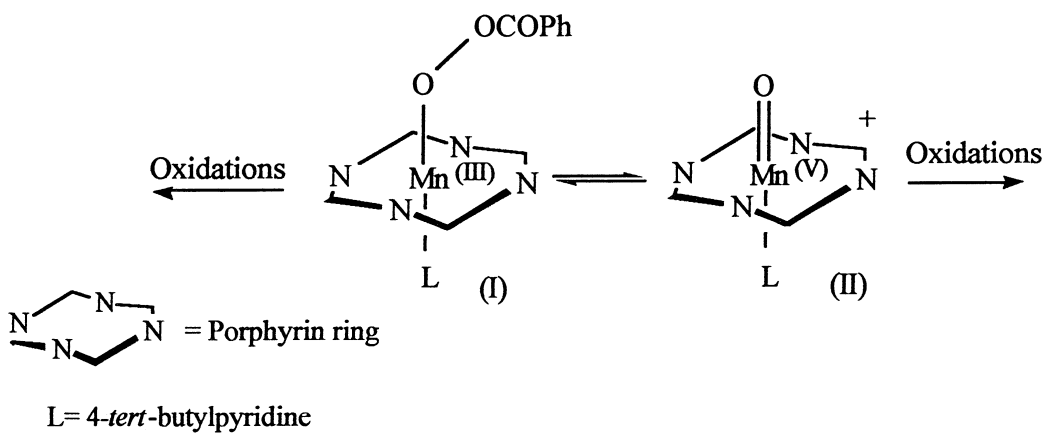

Scheme 1.

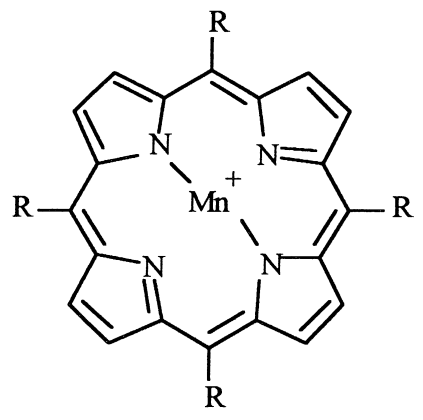<smiles>[R]c1c(Cl)ccc(S(=O)(=O)OCC)c1Cl</smiles>

Scheme 2.

However, the preceding mechanism does not explain the higher stability of the metalloporphyrin observed in the presence of the excess of benzoic acid [15].

In an attempt to clarify the problem, we decided to study the influence of the structure of the organic acid on rate of the epoxidation reaction. The epoxidation of cis-cyclooctene using the manganese complex of meso (2,6-dichlorophenyl) porphyrin (1) was performed in the presence of excess (20:1 relatively to catalyst $\mathbf{1})$ of different organic acids (Fig. 1). The substrate conver- sion yields were as shown in Fig. 1 and cis-cyclooctene epoxide was obtained with a selectivity higher than $90 \%$, in all cases, as observed by gas cromathography.

The experimental results show that the structure of the acid has a very significant influence on the rate of the reaction. Acids with the same or smaller $K_{\mathrm{a}}$ values than benzoic acid give faster reactions. On the other hand slower reactions occur with acids having a higher $K_{\mathrm{a}}$ than benzoic acid. Particularly slow reactions are observed in the cases of 2-chlorobenzoic and 2,4-dichlorobenzoic acids. The same behaviour is

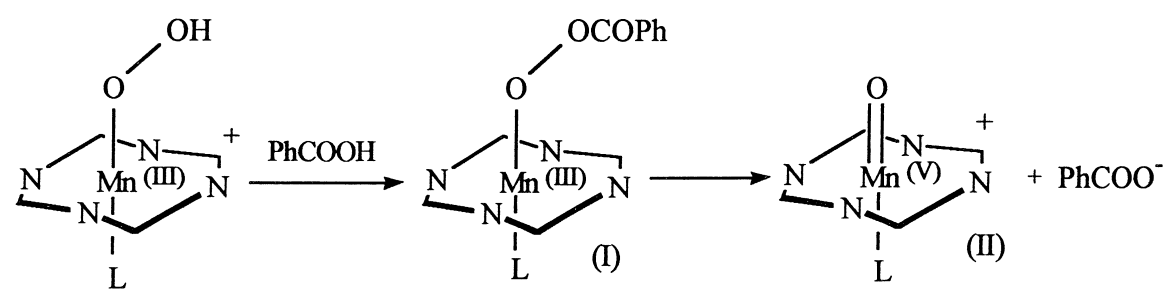

Scheme 3 . 


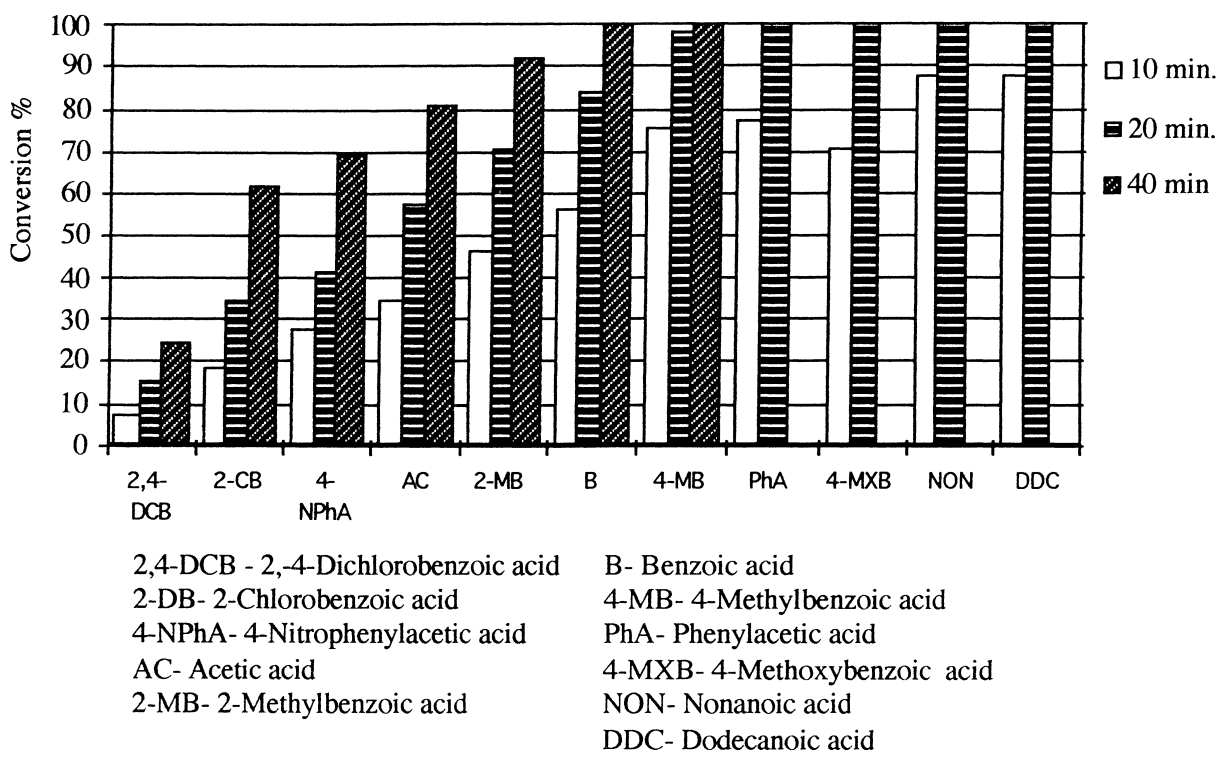

Fig. 1. Epoxidation of cis-cyclooctene catalysed by $\mathbf{1}$ in the presence of several organic acids. Reaction conditions: byphasic system; catalyst:4-tert-butylpyridine:organic acid:alkene: $\mathrm{H}_{2} \mathrm{O}_{2}(5 \%)=1: 1: 20: 300: 1300$ (except acetic acid with a 1:40 ratio).

observed in the case of the sulphonyl derivative 2 which has proved to be a more active catalyst than $\mathbf{1}$ [15] (Table 1).

The preceding results cannot be explained by the mechanism outlined in Scheme 3 [16,17]. In the metallo-acylperoxo species (I) the more acidic the acid the better leaving group would be the conjugate base. This would help the cleavage of the oxygen-oxygen bond to originate the metallo-oxo intermediate (II) and faster reactions were expected,

Table 1

Epoxidation of cis-cyclooctene catalysed by catalyst $\mathbf{2}$ in the presence of several organic acids ${ }^{\mathrm{a}}$

\begin{tabular}{lc}
\hline Organic acid & Conversion (\%) (min) \\
\hline Benzoic & $98(5)$ \\
& $100(10)$ \\
2-Chlorobenzoic & $62(10)$ \\
& $100(20)$ \\
2,4-Dichlorobenzoic & $50(10)$ \\
& $78(20)$ \\
& $100(50)$ \\
\hline
\end{tabular}

${ }^{a}$ Reaction conditions: byphasic system; catalyst:4-tert-butylpyridine:organic acid:alkene: $\mathrm{H}_{2} \mathrm{O}_{2}(5 \%)=1: 1: 20: 300: 1300$. contrary to what is observed. Montanari [18] stated once, without any further comment, to have observed that electron-withdrawing substituents on the benzoic acid slightly decrease the rate of epoxidation while electron-donating groups similarly increased the rate of the reaction.

Since it became apparent that the excess of benzoic acid directly intervenes on the mechanism of the reaction, we decided to clarify the role of the acid co-catalyst studying the influence of the same organic acids, previously studied, on the rate of epoxidation of cis-cyclooctene using this time a 1:1 ratio relatively to the catalyst 1 (Fig. 2).

The reaction rate in the presence of an equimolar amount of the organic acid is slower than the one observed when an excess is used. However, under these conditions and as shown in Fig. 2 the organic acids with electron-withdrawing substituents originate faster reactions than benzoic acid. Noteworthy are the cases of 2,4-dichlorobenzoic acid and 4-nitrophenylacetic acid which give even much faster reactions when the acid is present in an equimolar amount than in the presence of an acid excess. On the contrary the acids which gave the fastest reactions when used in 20:1 ratio, phenylacetic and nonanoic acid, gave the 


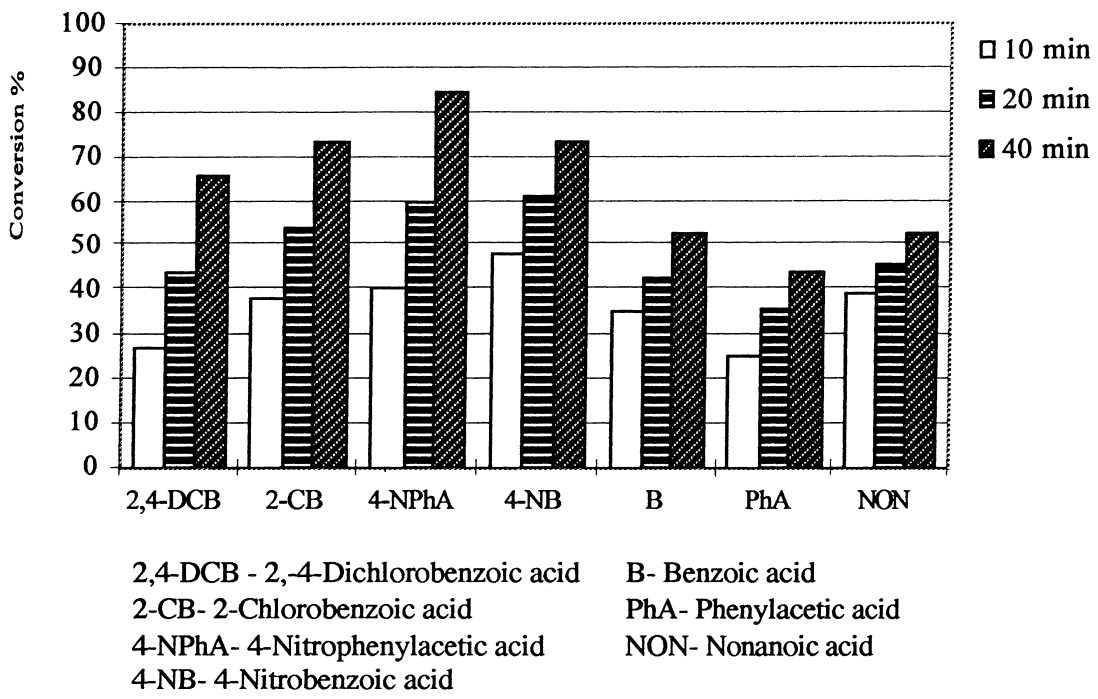

Fig. 2. Epoxidation of cis-cyclooctene catalysed by (1) in the presence of several organic acids. Reaction conditions: byphasic system; catalyst:4-tert-butylpyridine:organic acid:alkene: $\mathrm{H}_{2} \mathrm{O}_{2}(5 \%)=1: 1: 1: 300: 1300$.

slowest reactions when used in an equimolar amount. The mechanism presented in Scheme 3 is, therefore, suitable to explain the results of the reactions where equimolar amounts of the acid co-catalyst is used.

Concerning the stability of the catalyst to reaction conditions, it also proved to be highly dependent on the relative amount of organic acid used as shown in Fig. 3.

It is noteworthy that the catalyst is always more stable in the presence of an excess of organic acid such as previously shown for benzoic acid [15]. It should be emphasised that in the presence of excess of benzoic, phenylacetic and nonanoic acids the residual amount of catalyst is higher even after a larger number of catalytic cycles.

The preceding observations lead us to suggest two different and competitive mechanistic pathways for the oxidations under our reaction conditions (Scheme 4).

The metallo-hydroperoxo complex (III) species can follow two different interconnected pathways depending on the amount of organic acid. If only an equimolar amount of the acid is present, the route leading to the cleavage of the oxygen-oxygen bond and the formation of the metallo-oxo complex (II),

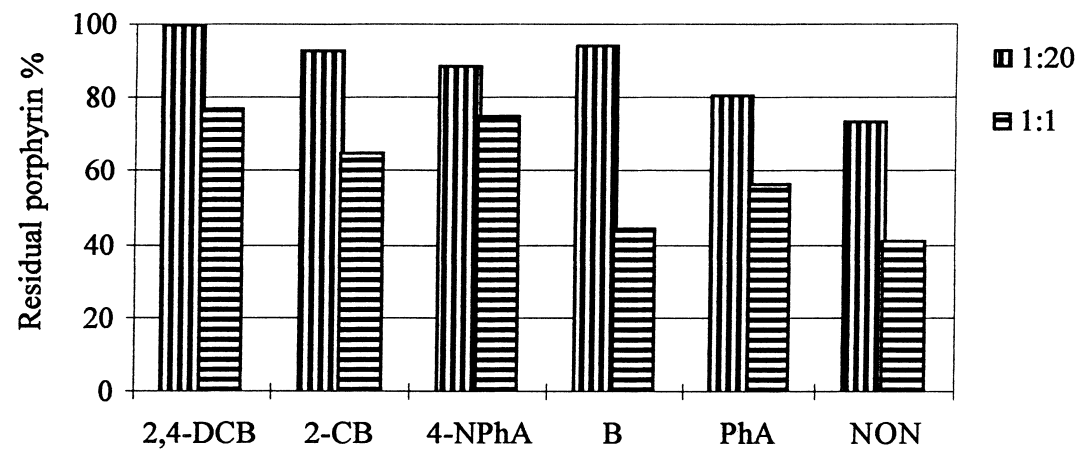

Fig. 3. Comparative values of the stability of the catalyst (1) in the reactions of Figs. 1 and 2. 


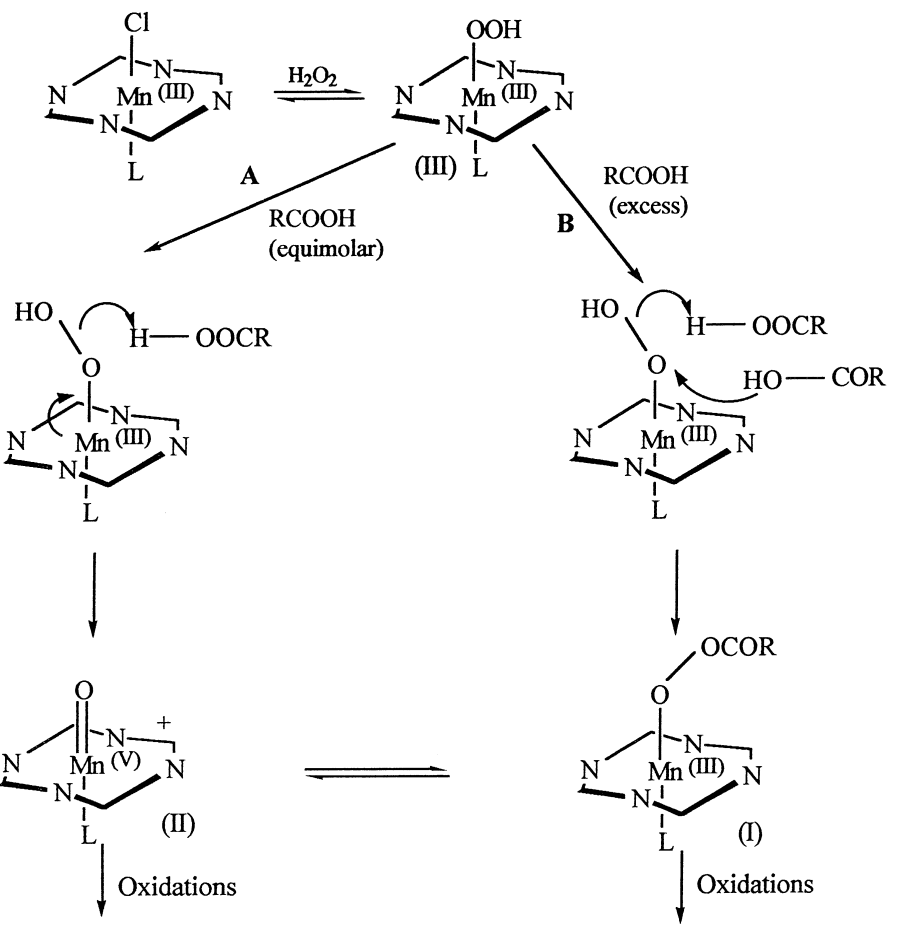

Scheme 4.

path A is dominant [19]. Stronger acids will be the most efficient, in this case, giving faster conversion of (III) to (II) as shown in the results of Fig. 2. In the presence of an excess of the acid co-catalyst, pathway $\mathrm{B}$ becomes the dominant one leading to the formation of the metallo-acylperoxo intermediate (I) by nucleophilic attack of a molecule of the acid to the oxygen atom near the metal and loss of a water molecule aided by a second molecule of the acid. This kind of attack was already suggested to explain the formation of intermediate (I) by organic acids [19-20] and the oxidation of sulphur compounds by co-ordinated hydroperoxo complexes [21].
The formation of the metallo-acylperoxo species (I) through pathway B can be favoured by a specific arrangement of the catalyst and organic acid at an interface region, as we have suggested before [22] (Scheme 5).

The excess of an acid co-catalyst having electronwithdrawing substituents does not benefit the formation of metallo-acylperoxo species (I) because the attack to the metallo-hydroperoxo species (III) by the nucleophile is less efficient. That type of acid also contributes to diminish the amount of species (III) which is available because it promotes the formation of the species (IV) having a carboxylate as axial

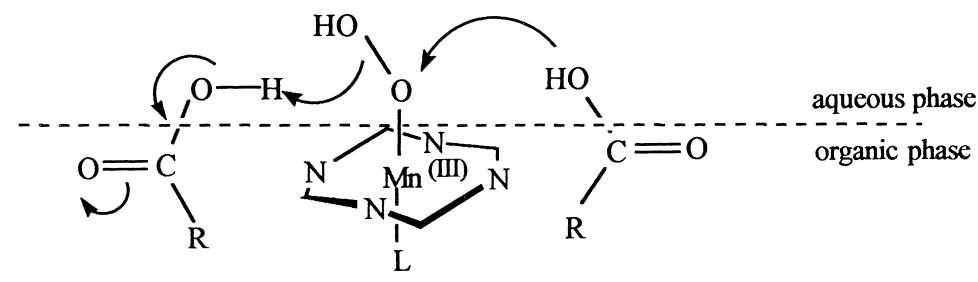

Scheme 5 . 


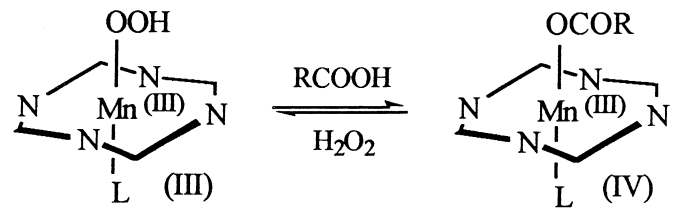

Scheme 6.

ligand [23] favouring the shift of the equilibrium shown in Scheme 6 to the right hand side.

The increased catalytic efficiency observed in the presence of excess of organic acid, particularly the increased stability of the catalyst, can be understood if the metallo-acylperoxo species (I) formed is reactive enough to directly oxidise the substrate without requiring its conversion to the metallo-oxo intermediate (II). By avoiding the formation of this highly oxidative species (II) which is referred as being directly related to the oxidative destruction of the macrocycle or axial ligand [24], route B contributes to the stability of the catalyst. In the presence of hydrogen peroxide, species (II) may favour the formation of reactive radicals [25] which can be directly responsible for the degradation of the catalyst.

The metallo-acylperoxo species resembling (I) was firstly suggested as the oxidising species by Watanabe et al. [14], and more recently the works of Nam [26] and Bandyopadhyay [27] showed that an metallo-acylperoxo complex is capable of directly oxidising substrates. Similarly metallo-acylperoxo complexes were also suggested as intermediates for epoxidations of alkenes with oxygen in a reaction where an aldehyde is the added co-oxidant [28,29]. Although the visible spectra of species (I) and (II) of pathways A and B must be distinct [30,31], we could not detect any spectroscopic difference for the solution either in the presence of equimolar or excess of benzoic acid. It is not unlikely that under the experimental conditions which were used, the amount of any of the species (I) or (II) may well be so low that they are not detected. They can be quickly reduced when formed, possibly by reaction with the hydrogen peroxide as proposed by Traylor [25].

We studied the stability of catalyst (1), measured by the value of absorbance for the Soret band, in the presence of different quantities of benzoic acid and in absence of alkene for a period of $60 \mathrm{~min}$. The results are plotted in Fig. 4.

This experiment showed that the catalyst is stable in the absence of substrate implying that the catalyst inactivation is promoted by intermediates generated in the catalytic cycle. A similar behaviour was referred to in methyltrioxorhenium catalysis [32]. In an experiment where an excess of cis-cyclooctene (200:1 relatively to the catalyst) was added after $40 \mathrm{~min}$ under the conditions described in Fig. 4 gave only $30 \%$ of conversion (either for benzoic acid/catalyst ratios of 20/1 and 1/1) after an extra $40 \mathrm{~min}$. This is to be expected if destruction of the axial ligand, required for an efficient catalytic process, occurred in the first 40 min making the reaction very slow under such conditions.

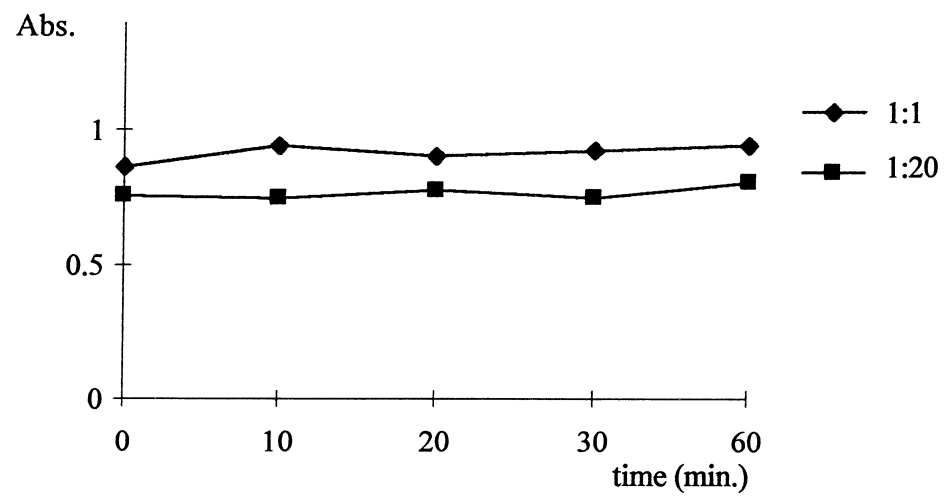

Fig. 4. Values of absorvances of samples of catalyst (1) subject to catalytic conditions but without substrate. Reaction conditions: byphasic system; catalyst:4-tert-butylpyridine:organic acid: $\mathrm{H}_{2} \mathrm{O}_{2}(5 \%)=1: 1: 1: 1300$ or 1:1:20:1300. 
Table 2

Epoxidation of cis-cyclooctene catalysed by catalyst $\mathbf{1}$ in the presence of organic acids in monophasic system ${ }^{\mathrm{a}}$

\begin{tabular}{ll}
\hline Organic acid & $\begin{array}{l}\text { Conversion } \\
(\%)(\mathrm{min})\end{array}$ \\
\hline Benzoic & $0(10)$ \\
& $0(20)$ \\
Phenylacetic & $4(10)$ \\
& $4(20)$ \\
4-Nitrophenylacetic & $4(10)$ \\
& $4(20)$ \\
\hline
\end{tabular}

${ }^{a}$ Reaction conditions: monophasic system; catalyst:4-tertbutylpyridine:organic acid:alkene: $\mathrm{H}_{2} \mathrm{O}_{2}(30 \%)=1: 1: 20: 300: 600$.

The possible existence of a relation between catalytic oxidative cycles and stability of the catalyst is consistent with our proposal that route $\mathrm{B}$, avoiding the metallo-oxo, explains the higher catalytic efficiency and catalytic stability observed with high concentration of carboxylic acid co-catalyst.

When replacing the reaction conditions of the oxidation system, by changing the medium from biphasic to monophasic by addition of methanol, the rate of epoxidation is greatly affected as registered in Table 2. The results show a complete suppression of the reaction which may be due to destruction of the interface and the organised structure proposed in Scheme 5. Another possibility is the formation of strong hydrogen bonds between methanol and the organic acids, like the ones which occur with benzoic acid [33], so blocking the formation of species (I) or (II).

\section{Conclusions}

The metalloporphyrin catalytic oxidations have been the object of intensive studies leading to the acceptance of a unique simple mechanism involving a metallo-oxo species as the direct oxidant of the substrates. In a two-phase system and with hydrogen peroxide as oxidant a careful study of the dependence of the efficiency and stability of the catalyst on the structure and amount of the carboxylic acid used as co-catalyst proved that the metallo-oxo oxidant intermediate cannot explain the observed behaviour and that a metallo-acylperoxo species is the more likely candidate to be the true substrate oxidant.

\section{Experimental}

Dichloromethane was distilled from $\mathrm{CaCl}_{2}$ before use. Methanol was dried and distilled. Others solvents used were commercially available and used as received. cis-Cyclooctene was obtained from Aldrich and passed through a short column of alumina before use. Hydrogen peroxide $5 \%$ was prepared before use from a concentrated solution from Riedel titrated by iodometry. The $\mathrm{pH}$ of this solution was set to 4.5-5 with hydrogen carbonate. Catalysts 1 and 2 were prepared following a previously described procedure [22]. Benzoic and 4-methylbenzoic acids was purchased from Fluka, 4-nitrophenylacetic and phenylacetic acids from Merck, acetic acid from Riedel, 2,4-dichlorobenzoic, 2-chlorobenzoic, 2-methylbenzoic, 4-methoxybenzoic, 4-nitrobenzoic, nonanoic and dodecanoic acids from Aldrich.

Gas chromatography analyses were performed on a Hewlett-Packard 5890A instrument with a flame ionisation detector and equipped with a Hp-Ultra-1 $(25 \mathrm{~m} \times 0.25 \mathrm{~mm}$, i.d.) capillary column. UV/visible spectra were obtained on a Hitachi-220S or on a Jasco 7800.

Catalytic reactions were carried out at room temperature. They were monitored by removing aliquots and examining the products by gas chromatography. The epoxide of cis-cyclooctene were identified by comparison of the chromatographic retention time with that of an authentic sample prepared independently and characterised by usual methods, NMR, MS and IR. Conversions are reported relatively to bromobenzene as internal standard.

General procedure for oxidation reactions: a $20 \mathrm{ml}$ flask is charged with $2.5 \times 10^{-3} \mathrm{mmol}$ of the metalloporphyrin and $2 \mathrm{ml}$ of a solution of organic acid in $\mathrm{CH}_{2} \mathrm{Cl}_{2}$ with a concentration that gave the desired organic acid/catalyst ratio. Then the internal standard, the axial ligand and the alkene were added. The reaction was started by addition of $2 \mathrm{ml}$ of hydrogen peroxide solution $(5 \%)$ and stirred at maximal rate. For monophasic system the organic acid were dissolved in $2 \mathrm{ml}$ of a solution of dichloromethane/methanol (1/1) and 30\% hydrogen peroxide was used. 


\section{Acknowledgements}

The authors would like to thank Chymiotechnon for financial support and Universidade Católica Portuguesa for leave of absence (ACS).

\section{References}

[1] J.T. Groves, M.K. Stern, J. Am. Chem. Soc. 110 (1988) 8628.

[2] J.T. Groves, J. Lee, S.S. Makla, J. Am. Chem. Soc. 119 (1997) 6269.

[3] N. Jin, J.T. Groves, J. Am. Chem. Soc. 121 (1999) 2923.

[4] J.T. Groves, R.C. Haushalter, M. Nakamura, T.E. Nemo, B.J. Evans, J. Am. Chem. Soc. 103 (1981) 2884.

[5] H. Fujii, J. Am. Chem. Soc. 115 (1993) 4641.

[6] Z. Gross, S. Nimri, J. Am. Chem. Soc. 117 (1995) 8021.

[7] Y. Mee Goh, W. Nam, Inorg. Chem. 38 (1999) 914.

[8] T. Hamada, T. Fukuda, H. Imanishi, T. Katsuki, Tetrahedron 52 (1996) 515.

[9] T. Linker, Angew. Chem., Int. Ed. Engl. 36 (1997) 2060.

[10] M. Palucki, N.S. Finney, P.J. Pospisil, M.L. Güler, T. Ishida, E.N. Jacobsen, J. Am. Chem. Soc. 120 (1998) 948.

[11] J.M. Pratt, T.I. Ridd, L.J. King, J. Chem. Soc., Chem. Commun. (1995) 2297.

[12] P.H. Toy, M. Newcomb, M.J. Coon, A.D.N. Vaz, J. Am. Chem. Soc. 120 (1998) 9718.

[13] Y.J. Lee, Y.M. Goh, S.-Y. Han, C. Kim, W. Nam, Chem. Lett. (1998) 837.

[14] K. Machii, Y. Watanabe, I. Morishima, J. Am. Chem. Soc. 117 (1995) 6691.

[15] A.M. d'A. Rocha Gonsalves, A.C. Serra, J. Porphyrins Phthalocyanines, in press.
[16] P.L. Anelli, S. Banfi, F. Montanari, S. Quici, J. Chem. Soc., Chem. Commun. (1989) 779

[17] S. Banfi, A. Maiocchi, F. Montanari, S. Quici, J. Chem. Soc., Chem. Commun. (1990) 1794

[18] S. Banfi, A. Maiocchi, F. Montanari, S. Quici, Gazz. Chim. Ital. 120 (1990) 123.

[19] P.L. Anelli, S. Banfi, F. Legramandi, F. Montanari, G. Pozzi, S. Quici, J. Chem. Soc., Perkin Trans. I (1993) 1345.

[20] S. Banfi, F. Montanari, G. Pozi, S. Quici, Gazz. Chim. Ital. 123 (1993) 617.

[21] S.A. Mirla, B. Bocquet, C. Robyr, S. Thomi, A.F. Williams, Inorg. Chem. 35 (1996) 1332.

[22] A.M.d'A. Rocha Gonsalves, M.M. Pereira, A.C. Serra, Anal. Quim. Int. Ed. 92 (1996) 375.

[23] M.W. Nee, J.R. Lindsay Smith, J. Chem. Soc., Dalton Trans. (1999) 3373.

[24] S. Quici, S. Banfi, G. Pozi, Gazz. Chim. Ital. 123 (1993) 597.

[25] T.G. Traylor, S. Tsuchiya, Y.-S. Byun, C. Kim, J. Am. Chem. Soc. 115 (1993) 2775

[26] K.A. Lee, W. Nam, J. Am. Chem. Soc. 119 (1997) 1916.

[27] K. Kamaraj, D. Bandyopadhyay, J. Am. Chem. Soc. 119 (1997) 8099.

[28] T. Yamada, K. Imagawa, T. Nagata, T. Mukaiyama, Bull. Chem. Soc. Jpn. 67 (1994) 2248.

[29] W. Nam, H.J. Kim, S.H. Kim, R.Y.N. Ho, J.S. Valentine, Inorg. Chem. 35 (1996) 1045

[30] J.T. Groves, Y. Watanabe, T.J. McMurry, J. Am. Chem. Soc. 105 (1983) 4489.

[31] J.T. Groves, Y. Watanabe, Inorg. Chem. 25 (1986) 4808.

[32] C. Copéret, H. Adolfsson, T.-A.V. Khuong, A.K. Yudin, K.B. Sharpless, J. Org. Chem. 63 (1998) 1740.

[33] P. Novak, D. Vikic-Topic, Z. Meic, S. Sekusak, A. Sabljic, J. Mol. Struct. 356 (1995) 131. 